\title{
Development of a technique of the automated construction of 3D models of standard mass transfer trays
}

\author{
Rimma Tukaeva ${ }^{1}$, Vitalliy Afanasenko ${ }^{1}$, and Petr Kulakov ${ }^{1, *}$ \\ ${ }^{1}$ Ufa State Petroleum Technological University, Ufa, 450062 Russian Federation
}

\begin{abstract}
The main elements of most mass-transfer columns of industrial enterprises are contact trays which are formed by various details inside the apparatus. The dimensions of the details are standardized and regulated by regulatory documents. under modern conditions of equipment designing it is necessary to develop three-dimensional model of typical assembly units, that is a very time-consuming task. The article considers the way to improve the design efficiency by automation of the process of standard mass-transfer valve tray model development in Kompas 3D system with MySQL application.
\end{abstract}

Nowadays, three-dimensional modelling provides great opportunities for facilitating and improving work in various spheres of human activity.

At the same time, the issues related to studying the possibilities of $3 \mathrm{D}$ modelling application for various oil and gas facilities designing, in particular, contact mass-transfer instruments of the column apparatuses, are extremely relevant. These instruments are widely used in the field of oil and gas processing. In this connection, it becomes necessary to understand their structure and principle of operation. Three-dimensional modelling makes it much easier to develop engineering drawings of these instruments [1-5].

Contact tray-type mass-transfer instruments are standard products and are manufactured in accordance with the corresponding regulatory document for the specified diameter of the apparatus body.

Based on the above mentioned, the issues of the present paper were formulated, which include the following:

- studying and analysis of modern computer-aided design (CAD) systems;

- selection of the optimal CAD system for 3D modelling of contact instruments;

- analysis of the current state of things in the field of development of 3D models of assembly units and details of different types of trays;

- consideration and analysis of structures and elements of mass-transfer instruments on the basis of normative and technical literature (GOSTs, ATCs, OSTs, etc.);

- development of the automated system for generation of three-dimensional models of basic elements of trays.

In the result of design systems comparative analysis, the product of the company "ASCON" - CAD "KOMPAS-3D" was chosen for further work. The choice in favor of this

\footnotetext{
* Corresponding author: kulakov.p.a@mail.ru
} 
design system was made on the basis of several factors: wide application of CAD, moderate price, great functionality, wide range of standard libraries, integration with other design systems, simplicity and promptness of learning, user-friendly interface, etc. [6-9].

Study of the current state of things in the filed of development of 3D models of column apparatuses internal contact instruments showed that today there are no catalogues or libraries containing visualized models of various devices and their details, developed on the basis of OSTs or other normative and technical documentation. Moreover, there is no automated system for three-dimensional models development [10,11].

In order to select modelling objects and prepare visualized models, studying of trays technical documentation was carried out. The analysis showed that nowadays the standardized designs of the following types of trays are mainly used: sieve, grid, valve and bubble-cap.

At the first stage of this work, the following objects were selected as the modelling objects: grid rectifying tray without overfill protection device (H964-63), valve tray with side overfill protection device (ATK 26-02-1-89), sieve tray with central overfill protection device (ATK 26-02-1-89).

At the second stage we determined how to develop a model using "KOMPAS-3D" system standard tools. So, for example for column apparatus elements modelling the solid modelling method and sheet articles modelling are more applicable. In the process of model development, operations of pressing out, rotation, cutting, arrays (Fig. 1), sheet body bending are sequentially applied. Performance of various combinations of these operations represents the process of a complex three-dimensional model development.

Then, main types of column apparatuses contact instruments normative structures were defined:

- database of typical tray elements geometrical dimensions was prepared and systematized;

- parametric models of various modifications of the valve tray with overfill protection device were developed;
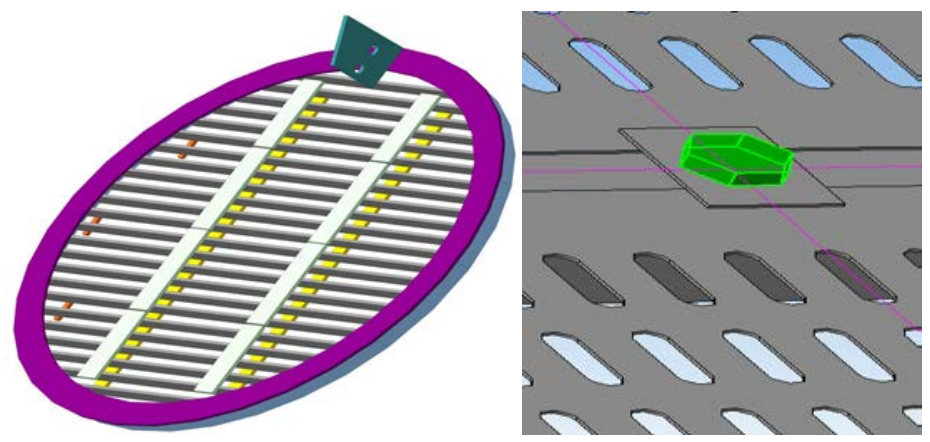

Fig. 1. Operation "Arrays".

Despite the fact that design of tray-type contact instruments have distinctive features, the process of their three-dimensional designing has common similar stages [13, 14]:

1) creation of an assembly in Kompas 3D;

2) contact instrument supporting structure development (sketch drawing, pressing out of parts);

3) placement of the gasket on the supporting structure surface;

4) tray deck model development;

5) performance of cuts in the deck;

6) development of the model of standard clamping elements located with the specified pitch; 
7) attachment of covers, overflow gates and other elements (Fig. 2).

For clarity, it is also possible to develop part of column apparatus body.

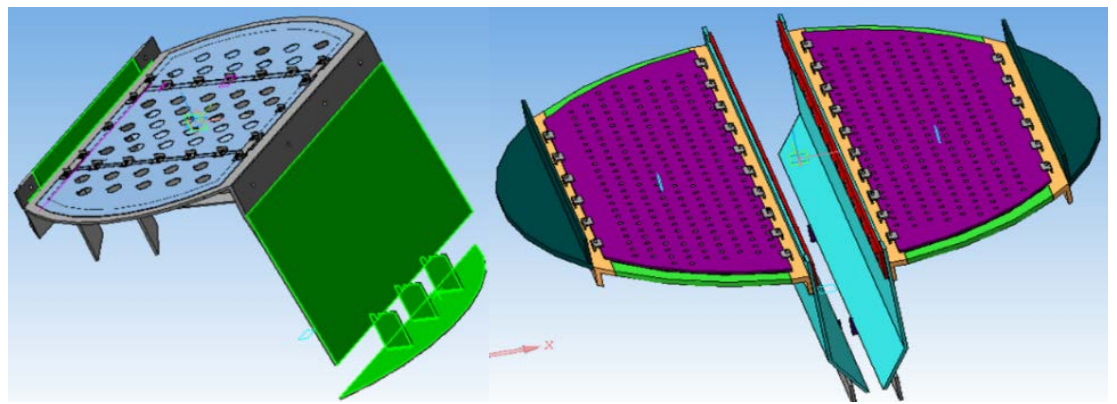

Fig. 2. 3D model of the tray.

Moreover, for the developed models, it is possible to make cross-sections in any planes.

Since there are several modifications and designs for one type of a tray, here arises the necessity of automation of the process of trays $3 \mathrm{D}$ models development. Like most CAD systems, Kompas 3D is provided with API system that allows adjusting the design system and performing development of additional software components in addition to those already available at the enterprise. Moreover, this CAD system is based on Core $3 \mathrm{D}$ geometrical core, which allows developing $\mathrm{CAD} / \mathrm{CAM} / \mathrm{CAE}$ system with good processing speed within a short period time.

At the first stage, requirements to the developed system are prepared. Figure 3 shows diagram of ways of system application.

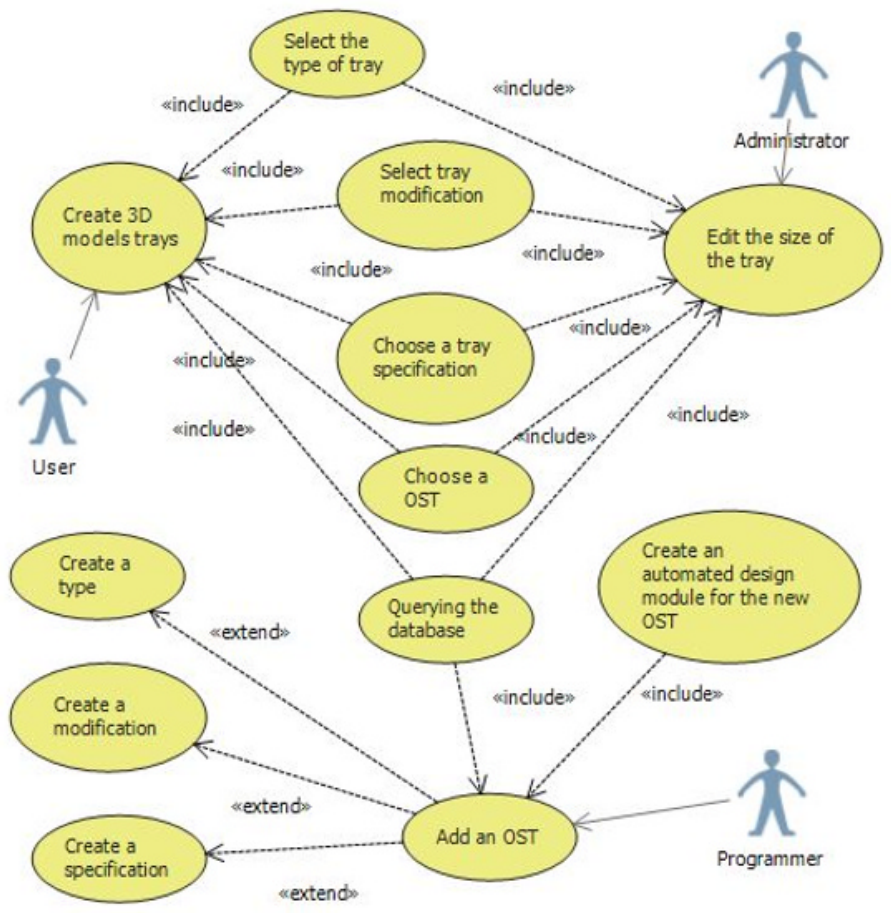

Fig. 3. Diagram of ways of application. 
The second stage requires development of the information model of the system (Fig. 4). MySQL was chosen as the DBMS, because it is a free product, it provides cross-platform ability, possesses acceptable processing speed and software support. The database consists of 6 main tables and an auxiliary table for fastening elements dimensions (it is not shown in the figure). The main Ost table contains data on the names of regulatory documents. The ParamKIPl tray parameters table, containing such parameters as diameter, column crosssection, tray total weight, including corrosion-resistant steel, is associated with the Ost table. As each tray has several modifications with identical set of parameters, the Modification table, containing data on geometrical dimensions of tray elements, was prepared. Since each modification contains three steps, in normal structure the database, the Step table, containing data on tray deck, quantity and dimensions of cut-outs, was prepared. The Size table contains all possible dimensions of the tray for different designs. In case of using trays welded to the body of the apparatus, refer to the SizeWelding table.

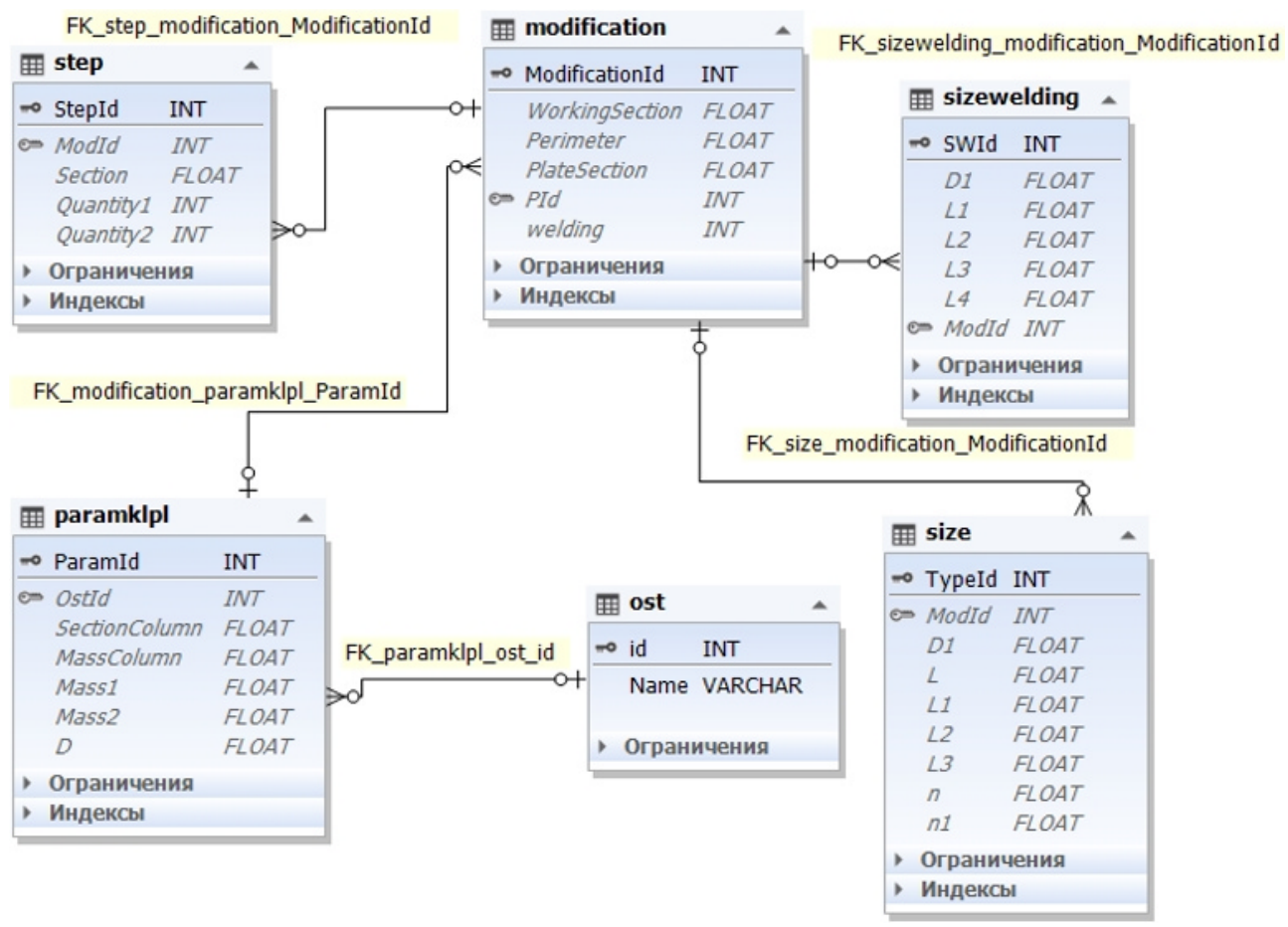

Fig. 4. System information model.

User of the application (Fig. 5) can select the normative document, parameters of the tray design, then select the modification of the tray and pitch of the valves. There is also support of the tray fixation by welding. 


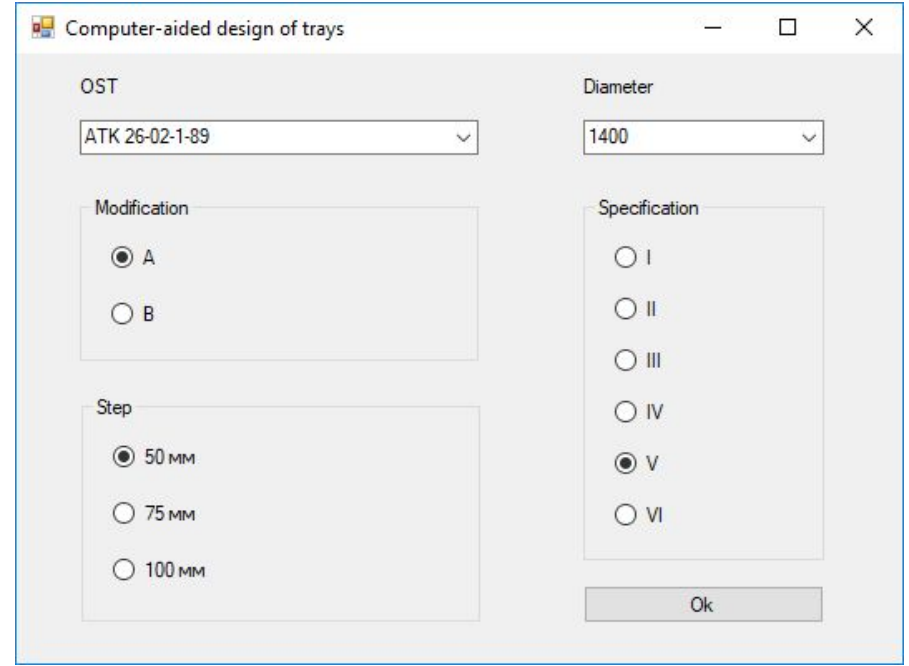

Fig. 5. Software configuration.

Thus, when the normative document is changed, it is possible to add additional parameters of the initial data for the trays or change the existing ones. However, when you add tray of a completely new design, involvement of the programmer is required.

\section{Conclusion}

In the result of the performed work:

- scientifically well-grounded algorithm of mass-transfer trays 3D models development was generated;

- main types of column apparatuses contact instruments normative structures were defined;

- typical tray elements geometrical dimensions were analysed and systematized;

- parametric models of the model typical structures were developed at the first stage in accordance with ATK 26-02-1-89;

- information model of the contact instrument was developed with the application of MySQL DBMS and dbForge Studio design environment;

- applied software for mass-transfer tray automatic designing with the application of Kompas 3D libraries was developed.

Further work is aimed at automation of three-dimensional modelling of other types of tray-type instruments of mass-transfer apparatuses and spread-out of standard parts database.

All this will make it possible to improve efficiency of column apparatuses contact instruments drawings preparation and will speed up preparation of normative and design documentation. Moreover, this could be applied for the educational process to train students connected with development, design, installation and repair of mass-transfer trays.

\section{References}

1. Dmitrieva O.S., Dmitriev A.V., Madyshev I.N., Nikolaev A.N. Flow dynamics of mass exchangers with jet-bubbling contact devices// Chemical and Petroleum Engineering, P. 1-5 (2007)

2. Solodovnik D.V., Kunina P.S., Boiko S.I. Overview of centrifugal mass-transfer instrument modern structure, № 8, P. 47-50 (2015) 
3. Madyshev I.N., Dmitrieva O.S., Dmitriev A.V., Nikolaev A.N. Study of fluid dynamics of mass-transfer apparatuses having stream-bubble contact devices// Chemical and Petroleum Engineering, Vol. 52 № 5-6, P. 299-304 (2016)

4. Umergalin T.G., Umergalina T.V. Calculation of heat-mass-transfer of the step of multicomponent mixture contact// Bashkir chemical journal, Vol. 23 № 2, P. 41-43 (2016)

5. Boev E.V., Ivanov S.P., Afanasenko V.G., Nikolaev E.A. Polymeric drop-film sprinklers for cooling towers// Chemical and Petroleum Engineering, Vol. 45 № 7-8, P. 454-459 (2009)

6. Masyagin V.B., Mukholzoev A.V., Shaimova S.B. Ways of automation of technological processes dimensional analysis in Russia// Fundamental research, № 6-1, P. 44-49 (2015)

7. Dudko O.N., Nelyubina A.D., Kozhevnikova N.Yu., Khasanov A.R. Overview of the automated design system// Modern materials, engineering and technology, № 2 (2), P. 51-54 (2015)

8. Samarkin A.I., Samarkina E.I., Dmitriev S.I., Evgenieva E.A. Overview of modern CAD systems// Bulletin of the Pskov State University. Series: Engineering sciences, № 5, P. 18-24 (2017)

9. Danchenko T.V., Trubnikova I.S., Perkova M.A. CAD systems in the educational process// Transport facilities, Vol. 4 № 4, P. 8 (2017)

10. Pochatkova S. Kompas-graph V16: New "three-dimensional" products for work on a plane// CAD and graphics, № 5 (223), P. 36-39 (2015)

11. Kidruk M. Original application for kompas-3d. automation of reduction gears designing// CAD and graphics, № 11, P. 7 (2005)

12. Kapranov A.E., Pris N.M. Development of the library of three-dimensional parametric models of universal assembly devices// Engineering sciences - from theory to practice, № 45, P. 45-50 (2015)

13. Sergeev S.A., Barzykina G.A., Sergeeva E.A. Development of the method of automated designing on the example of chain couplings// Up-to-date fields of scientific research of the XXI century: theory and practice, Vol. 3 № 7-2 (18-2), P. 437-440 (2015)

14. Antipina L.A. Development of the uniform $3 D$ object-parametric model for OPS designing// Pipeline oil transportation, № S6, P. 18-22 (2008) 